\title{
Who gets the benefits? An approach for assessing the environmental performance of industrial symbiosis
}

Michael Martin, Niclas Svensson and Mats Eklund

\section{Linköping University Post Print}

\section{Tweet}

N.B.: When citing this work, cite the original article.

Original Publication:

Michael Martin, Niclas Svensson and Mats Eklund, Who gets the benefits? An approach for assessing the environmental performance of industrial symbiosis, 2013, Journal of Cleaner Production.

http://dx.doi.org/10.1016/j.jclepro.2013.06.024

Copyright: Elsevier

http://www.elsevier.com/

Postprint available at: Linköping University Electronic Press

http://urn.kb.se/resolve?urn=urn:nbn:se:liu:diva-90232 


\title{
Who gets the benefits? An approach for assessing the environmental performance of industrial symbiosis
}

Michael Martin¹, Niclas Svensson and Mats Eklund

Linköping University, Environmental Technology and Management, SE-581 83 Linköping, Sweden

\begin{abstract}
Industrial symbiosis networks are generally assumed to provide economic and environmental benefits for all firms involved, though few quantifications have been produced in the literature, and the methods for these quantifications have varied. This paper provides an approach to quantify environmental performance of industrial symbiosis using guidance from the literature of life cycle assessment. Additionally, an approach to distribute credits due to exchanges for firms in the industrial symbiosis network is outlined. From the approach, influential methodological considerations used for the quantifications are discussed, including e.g. the production of reference systems, allocation methods, system boundaries and functional unit. The implications of such an approach may be beneficial for the industrial symbiosis community and provide information crucial for taxes, subsidies, business relations, expansion possibilities for the network, marketing and other issues related to the environmental performance of firms in the industrial symbiosis network.
\end{abstract}

\section{Keywords}

Industrial symbiosis, life cycle assessment, by-product, integration, environmental performance

${ }^{1}$ Corresponding Author. Tel: +46 13281132, Email: michael.martin@liu.se 


\section{Introduction}

Industrial symbiosis (IS) is a research topic from the field of industrial ecology which investigates all aspects of inter-firm symbiotic activities. The aims of these symbiotic activities are to engage traditionally separate industries to cooperate collectively to create competitive advantages and "win-win situations" for the firms involved. This is done through the creation of exchanges to optimize the material cycles and energy flows, analogous to natural ecosystems (Chertow, 2000).

Industrial symbiosis has been identified as an approach to improve material and energy efficiency in industrial systems (Chertow and Lombardi, 2005; Martin and Eklund, 2011; Wolf and Karlsson, 2008). However, industrial symbiosis is assumed to produce benefits for all firms involved in the exchanges, though studies concerning the economic, environmental and social benefits as well as the benefits for firms involved in the industrial symbiosis network are rare in the literature. The few quantification studies that are available typically analyze the impacts of the industrial symbiosis networks for selected exchanges or review the entire IS network (Mattila et al., 2010; Sokka et al., 2011; Wolf and Karlsson, 2008), comparing an existing industrial symbiosis network to a stand-alone situation. Hitherto, the distribution of impacts and benefits to firms of the industrial symbiosis networks has not been applied. As the goal of industrial symbiosis is to create win-win situations for all firms involved, it is important to attempt to provide these gains by portraying more than the overall impacts or benefits of the IS network. Tools for quantifying the environmental performance, such as life cycle assessment (LCA), from the industrial ecology toolbox are seldom applied (Wolf and Karlsson, 2008). Furthermore, no standardized guidelines are available for how to quantify the benefits or impacts of industrial symbiosis networks (Mattila et al., 2012; Mattila et al., 2010; van Berkel, 2010).

This paper aims to contribute to the industrial symbiosis literature with an approach to assess the environmental performance of industrial symbiosis networks based on life cycle assessment literature and guidelines. This is done in order to aid the quantification of the environmental performance of IS networks for IS practitioners of current IS networks or possible improvements in comparison to reference scenarios. The approach produced also offers a method for distributing the environmental impacts and benefits from exchanges to firms in the industrial symbiosis network in addition to providing the total impacts of an IS network. Furthermore, the approach aims to provide important methodological considerations for conducting the environmental performance quantifications of IS networks to connect the fields of IS and LCA. 


\section{Background to the Approach}

In the literature available for industrial symbiosis, firms of an IS network are assumed to benefit from the exchanges of material and energy, though few studies provide quantifications of the economic and environmental benefits (Sokka et al., 2011; Sokka, 2011; van Berkel, 2010; Wolf and Karlsson, 2008). Nonetheless, several studies have reviewed the environmental and economic improvement possibilities, though they are limited to a select few exchanges from the IS network; see e.g. (Jacobsen, 2006; Martin et al., In Press; Singh et al., 2007). Quantifications of the impacts from an entire IS network are also available; see e.g. (Mattila et al., 2010; Sokka et al., 2011; Wolf and Karlsson, 2008). In a recent study by Matilla et al. (2012), a review is provided on the research questions addressed by previous studies of the environmental performance or possibilities for improvements of IS networks. It was found that previous studies have aimed at providing an analysis of current environmental performance of IS networks in addition to impacts from improvements and expansion possibilities of the IS network. Further research questions also addressed the impacts from the creation of new eco-industrial parks and even studies reviewing other options versus IS networks, e.g. the design of circular economies.

From previous studies, LCA was found to be a feasible tool for the quantification of environmental performance of IS networks in order to capture all elements of the environmental performance (Mattila et al., 2012; Singh et al., 2007; Sokka et al., 2011), to answer the research questions addressed by the studies. Nonetheless, it has been recognized that methodological choices for the assessments have varied in the absence of agreed rules, methods and indicators, thus constraining sustainability assessments of industrial symbiosis networks (Martin et al., 2012; Mattila et al., 2012; van Berkel, 2010). Matilla et al. (2012) and Martin et al. (2012) provide a discussion on the methodological considerations and transparency of their use in previous studies, including the functional unit, reference system, allocation methods and system boundaries for the assessment and how they may influence the results.

Recommendations are provided in the study by Matilla et al. (2012) to conduct quantifications of the environmental performance of IS networks, using LCA literature for guidance. However, the paper provides recommendations for providing the environmental performance of the total output of the system. By providing only the total impacts of the IS network, studies may fail to present employable data for firms in the IS network. Therefore, in order to extend the recommendations of Matilla et al. (2012) to address the environmental performance of individual firms in the IS network, and how the firms may benefit from being part of the IS network, an approach has been provided to guide the quantifications. The approach will also address many of the methodological considerations 
when conducting the quantifications using LCA guidelines, see e.g. (European Commission, 2010; ISO, 2006a; ISO, 2006b).

\section{Approach to Quantify the Environmental Performance of Industrial Symbiosis Networks based on LCA literature}

An overview of the important steps and choices of the approach are illustrated in Figure 1. The steps are once again based on the elements of conducting an LCA. First the goal and scope of the study is to be defined, including the choice of functional unit, system boundaries, by-products, impact categories to be included and data quality. Thereafter, it is recommended that the existing system be compared with a reference system, which should be modeled. In order to conduct the quantifications allocation methods are chosen. For each allocation method certain aspects are to be determined, including allocation parameters and avoided products or raw materials. Thereafter, the quantifications can ensue for either the total system or the individual firm impacts and the results can be compared.

The following sections will provide methodological considerations and recommendations for applying LCA to quantify the environmental performance of industrial symbiosis networks. 


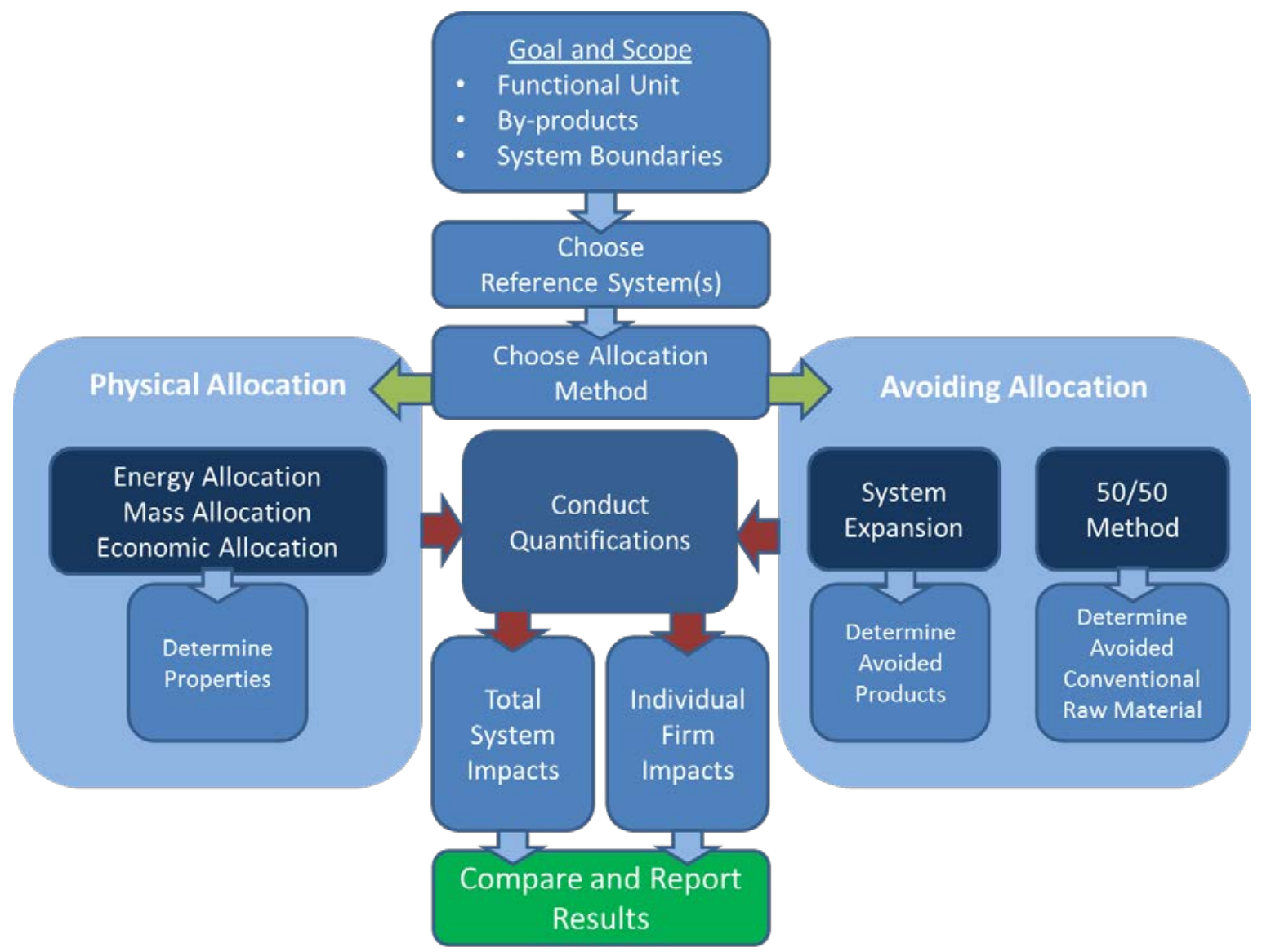

Figure 1: Overview of the steps and choices made in the approach provided in this paper to quantify IS networks

\subsection{Goal and Scope of the IS network quantification}

Fundamental to the quantification of an IS network are the goal and scope definitions. The goal and scope element of the LCA ensures that the outcome is consistent with the objectives and sets the context for the study (ISO, 2006a; ISO, 2006b). The choice of important elements in the goal and scope are outlined in the proceeding text.

\subsubsection{Functional Unit}

When reviewing the environmental performance of an industrial symbiosis network, the choice of functional unit can create difficulties. Choosing the total output of the system, in the case for previous industrial symbiosis quantifications, may cause difficulties when comparing to a reference system. Again, the outputs change, thus changing the functional unit. In order to overcome this, the purpose of the industrial symbiosis network and assessment can be viewed corresponding to the definition of the functional unit.

The industrial symbiosis network can be viewed as a multi-functional system, producing several main products and a number of by-products. If the goal of the assessment is to assess the possible benefits or impacts of the industrial symbiosis network and the 
implications for the firms involved, the main products of the firms are set as the functional unit(s) of the system. This is done so that the impacts can be allocated to firms in the IS network. Additional products of the system are considered by-products and are allocated impacts or benefits from the avoidance of processes as described in subsequent text. Weidema (2001) distinguishes main products of the system, or the determining product, as the products which determine the output from the respective production process. Byproducts constitute those products which are dependent upon the main products.

The reference scenarios, as well as scenarios with improvements, are created to produce the same functional unit (same quantity of main products) as the existing scenario in order to allow for comparisons. The comparison of these scenarios allows for the assessment of how these changes affect the system. Thereafter, the production of by-products in varied volumes can be handled by system expansion or other allocation methods.

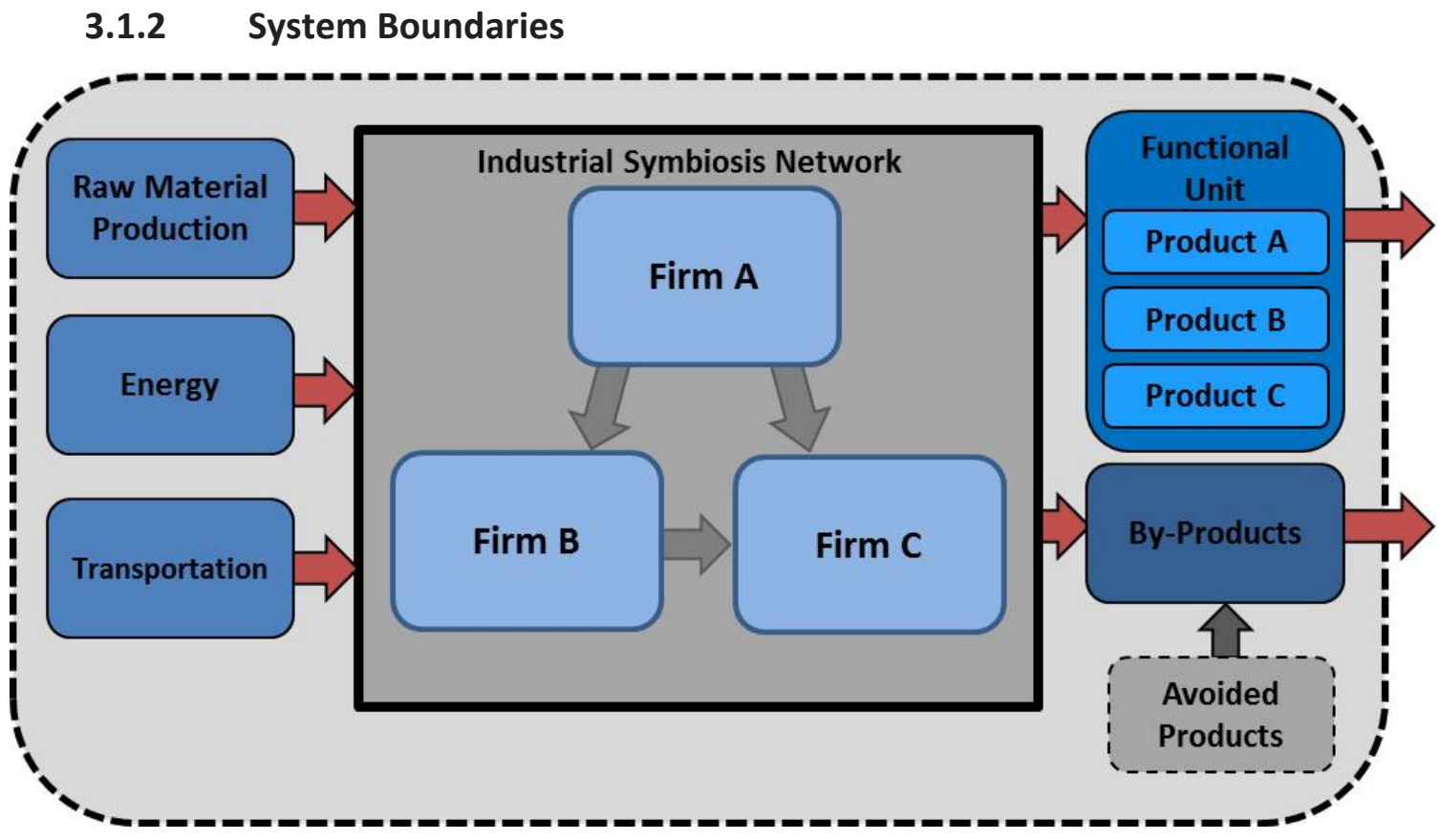

Figure 2: System Boundary for Industrial Symbiosis Network

With the aim to quantify the environmental performance of an industrial symbiosis network, the system boundaries must cover all resource and energy consumption used for raw materials and transportation for each firm; in addition to impacts of the IS network. Therefore, the LCA must cover at least the cradle-to-gate to ensure upstream impacts are taken into account, see Figure 2. By ending at the "gate" or products leaving the system, the analysis can compare the industrial symbiosis network compared to other scenarios and changes to the system. The benefits from avoided products, due to the production of byproducts from the system, are also included. 
Based on the approach of Mattila et al. (2012), downstream impacts may also be included for studies on the effects to systems beyond the industrial symbiosis network, i.e. by extending the system boundaries. However, the approach outlined in this paper provides support for quantifications related to the analysis of environmental performance of existing industrial symbiosis networks, improvements and possibly expansion possibilities as the aims suggest.

\subsubsection{Data Collection and Impact Categories}

Data used for the quantifications should represent actual conditions as well as possible. Primary data for the firms of the IS network should be compiled for the inputs and outputs of the system and emissions from production processes. This may require averaged data from producers (over some specified time periods) to avoid providing data which may not be representative of the general situation. Secondary data, from literature or databases, may thereafter be used for other processes in the life cycle if primary data is not included (European Commission, 2010). All assumptions and data sources should be transparent.

Impact categories chosen should be robust and reflect global and local emissions in order to take into account impacts created by the use of material and energy by the industrial symbiosis network. Greenhouse gas emissions, i.e. carbon dioxide equivalent emissions $\left(\mathrm{CO}_{2}\right.$-eq), should be reviewed to allow for comparisons with other IS networks, as $\mathrm{CO}_{2}$-eq emissions are used for many life cycle assessments.

\subsection{Reference Scenario Selection}

To allow for quantification of possible benefits and impacts of an existing industrial symbiosis network, reference scenarios are created for comparison with the existing case. The reference scenarios created are only a speculative representation of what would have happened if the exchanges had not taken place. Based on an available understanding of the current system, metabolism of products from the system and regional data are used to construct reference scenarios. The reference scenarios chosen must be thoroughly described and motivated, e.g. materials, energy, transportation choices, etc., when no symbiotic activity is present.

It is recommended that several reference scenarios are produced in order to provide a diverse counterfactual analysis of the reference system (Sokka, 2011). By producing several reference scenarios, a sensitivity analysis based on different choices will be accomplished. One of these reference scenarios could take into account marginal systems of the region (Weidema et al., 1999; Wolf and Karlsson, 2008) with recommendations for choosing the marginal technology provided by Ekvall and Weidema (Ekvall and Weidema, 2004). For example, if the existing industrial symbiosis network receives excess process heat from a neighboring firm, a marginal system for the purpose of providing heat could be modeled in one of the reference scenarios. 
A review of possible uses and optimization of the by-product streams produced from the reference scenarios is also recommended, as a simple substitution of conventional products may not be applicable. For example, consideration must be made for adding value to the byproduct stream through the production of other products, reduction of by-product streams and optimization of the process. Figure 3 represents some possible reference scenarios for a single firm. Assuming the functional unit is defined as Product A, impacts are allocated or deducted from Product A depending upon the use of physical allocation or system expansion.

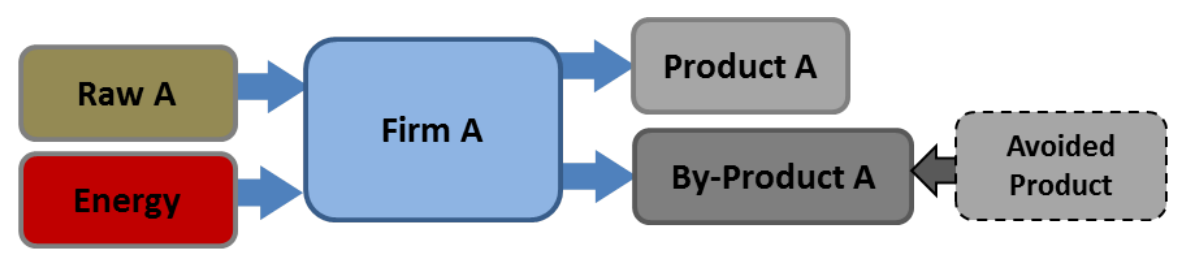

a)

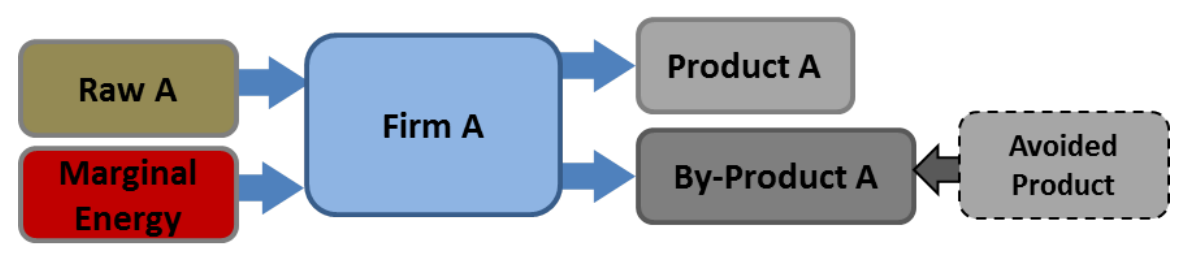

b)

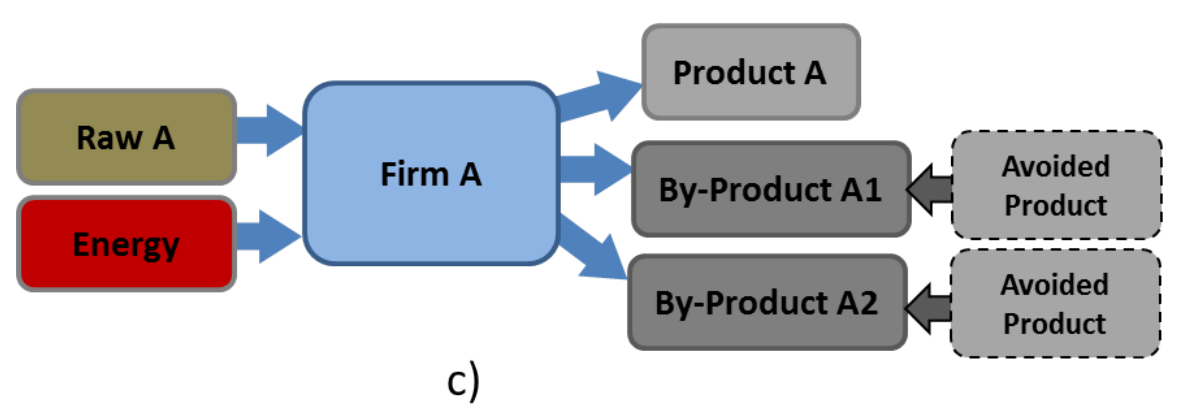

Figure 3: Examples of possible reference scenarios for one firm of the industrial symbiosis network, i.e. Firm A, to model options for the handling of By-Product A. The scenarios depict the a) original reference scenario, b) a reference scenario with changed marginal energy source and c) a reference scenario with new by-product streams.

\subsection{Distributing Impacts and Credits in the IS Network}

As the functional unit(s) of the industrial symbiosis network are to be set as the main products of the system, by-products of the system must be accounted for by either partitioning the impacts or avoiding impacts from conventional products replaced by the by-products. However, allocation of impacts in multifunctional LCAs, i.e. producing multiple products, is a highly controversial (Ekvall and Finnveden, 2001). Guinée et al. (Guinée et al., 2004) claim that there is is no "correct" way to resolve this problem although the solution 
should be consistent with the main methodological choices made. Nonetheless, using recommendations provided by Mattila et al (2012) can aid in choosing the type analysis, and ultimately the type of allocation method to be used. From the recommendations provided by Mattila et al. (2012), the type of analysis to be conducted when quantifying the environmental performance of the IS networks is provided, i.e. attributional or consequential $^{2}$ modeling; which is based on the International Reference Life Cycle Database (ILCD) guidelines (European Commission, 2010). It is recommend that attributional methods are used when modeling environmental performance quantifications of IS networks for analysis of current IS networks and improvement purposes. When quantifying the environmental performance of expansion possibilities, attributional methods may be used, though if the influence on the background economy becomes substantial, consequential modeling is recommended. Consequential modeling is also recommended for quantifications of the environmental performance of studies reviewing the design of ecoindustrial parks and circular economies; see Mattila et al. (2012) for further details.

In this paper, which aims at providing the environmental performance of current IS networks or possible improvements in comparison to reference scenarios attributional modeling is recommended. In the following sections, recommendations are given for the use of both physical allocation and avoiding allocation with the system expansion method. It is also recommended that both methods are used to show the influence on the results.

\subsubsection{Physical Allocation of Impacts in the Industrial Symbiosis Network}

Using attributional modeling allows for physical allocation to be applied to partition impacts for multi-functional processes. However, the physical parameter to compare and partition impacts to the products and by-products must be chosen, which can include e.g. energy, economic, mass or exergy allocation. This may be a difficult choice, as the inherent energy and mass may partition more impacts to by-products of the system and provide diverging results to the system (Cherubini, 2010; van der Voet et al., 2010). Nonetheless, some authors recommend physical allocation, as measureable data can be used for partitioning the impacts (Heijungs and Guinée, 2007).

\footnotetext{
${ }^{2}$ Attributional LCAs typically use physical allocation methods to partition environmental impacts to products from the system, including e.g. energy, mass or economic values of the products using average data. Consequential LCAs, on the other hand, typically expand the system boundaries to include affected parts of other life cycles due to changes in the system, using marginal data, and are conceptually more complex (Finnveden et al., 2009).
} 


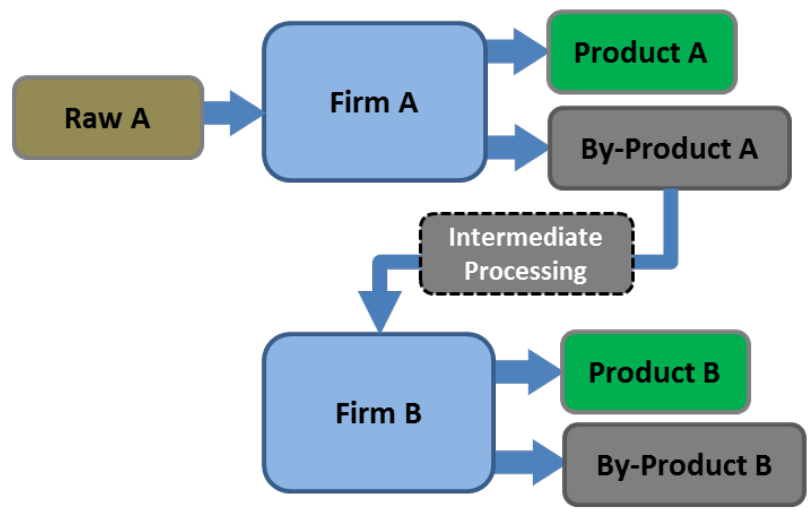

a)

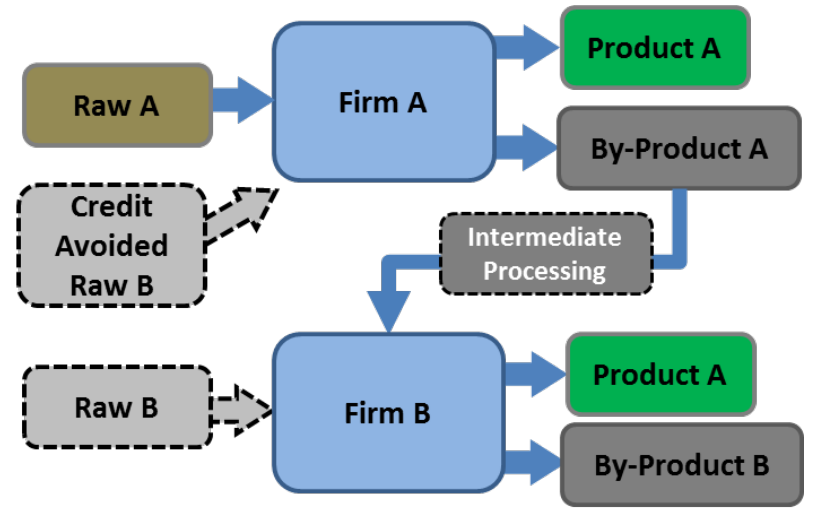

b)

Figure 4: Illustration of an exchange between Firm A and B, including possible intermediate processing, for representing the a) physical allocation method and b) the system expansion method.

In Figure 4(a), Firm A produces both Product A and By-Product A. Thereafter, By-Product A is used in Firm B to produce Product B. Using physical allocation to partition the impacts would allow By-Product A to enter Firm B with a share of the impacts from Firm A. This share of impacts depends on the physical parameter used to partition the impacts. If intermediate processing is required for By-Product $A$, the impacts from the intermediate process would be allocated to the product leaving the intermediate process and are therefore added to the impacts from By-product A to Firm B.

\subsubsection{Avoiding Allocation in the Industrial Symbiosis Network}

The system expansion method to avoid allocation is the preferred method of ISO (ISO, 2006a). Weidema (2001) also suggests that physical allocation methods are nearly always avoidable and that system expansion is preferable. The system expansion method is considered a form of consequential modeling, also referred to as partial-consequential modeling, for the avoidance of processes created by by-products of the system which affect markets outside the system (Zamagni et al., 2012). However, many LCA practitioners use average data for the assessments and it is conducted similar to an attributional type of LCA. Using the system expansion method, by-products will replace conventional products, and therefore the impact of producing the equivalent amount of conventional products will be removed from the system.

The determination of avoided conventional products is thus important in the system expansion method. Ekvall and Finnveden (2001) argue that it is important that there is a market capable of absorbing these by-products, and care must be taken when choosing the avoided conventional products. It is recommended that the identification of avoided processes be produced similar to the approach provided by Weidema et al. (1999) and Ekvall and Weidema (Ekvall and Weidema, 2004) where a comprehensive review of processes affected by changes in demand is produced to identify avoided products by 
taking into account size, time, geographic, economic and other aspects of the change in production. The choice again should be transparent.

When a by-product is utilized in another industry through an exchange, the system expansion method may not allow for the impacts to be shared among firms. In the method produced by Weidema (2001), this weakness can be avoided by crediting the firm delivering the by-product with the avoided conventional raw material, i.e. deducting the impact for the production of the conventional raw material. To illustrate this, see Figure 4(b). Firm A provides By-product A to Firm B, which substitutes Raw B. By substituting the conventional production of Raw B, Firm A is credited in the system expansion method. However, Firm B still receives the impacts from the production of Raw B in order to model changes in the system for displacing Raw B. This must be accomplished, otherwise both Firm A and B would receive all the credits for the removal of Raw B. However, in this model, Firm B does not receive any credits for the use of By-Product A. Furthermore, any impacts from an intermediate process to process By-Product A would be received by Firm A.

Nonetheless, if the method of Weidema (2001) is used, the impacts and benefits from the use of by-products as raw materials may not be fairly distributed between the firms from an exchange. In order to fairly distribute the credits between Firms $A$ and B, the quantifications may borrow from open-loop recycling literature. In the open-loop recycling literature, a distribution of impacts is conducted for firms involved in the processing and use of raw materials and recycled materials (Ekvall and Tillman, 1997). Within the openloop recycling literature, the 50/50 method is often referred to in order to distribute credits and impacts of recycling processes between the producer and final consumer of a recycled product or material. The rule was created due to the fact that recycling and exchanges are implemented from a supply and demand viewpoint to encourage recycling. In the 50/50 method, impacts are allocated to both the firm initially using a raw material as well as the firm later receiving the material after several recycling steps to share the impacts between life cycles (Ekvall and Tillman, 1997; Ekvall, 2000). This chain of recycling and cascading may be large and can lead to difficulties to distribute the credits between the companies using the raw materials and recycled materials in addition to the concern that materials may not be fully utilized. However, since such a large chain of recycling and cascading is not present in many industrial symbiosis networks, inspiration from the 50/50 method can be used to distribute impacts and credits to companies directly involved in the exchange.

\subsubsection{Applying a distributed credit system (50/50 method)}

For industrial symbiosis networks, an approach can be used to distribute the credits to firms involved in an exchange. This distributed credit method, referred to as the 50/50 method hereafter, can be used to distribute of credits from the replacement of a conventional raw material to firms involved in an exchange by the use of a by-product as a raw material. 


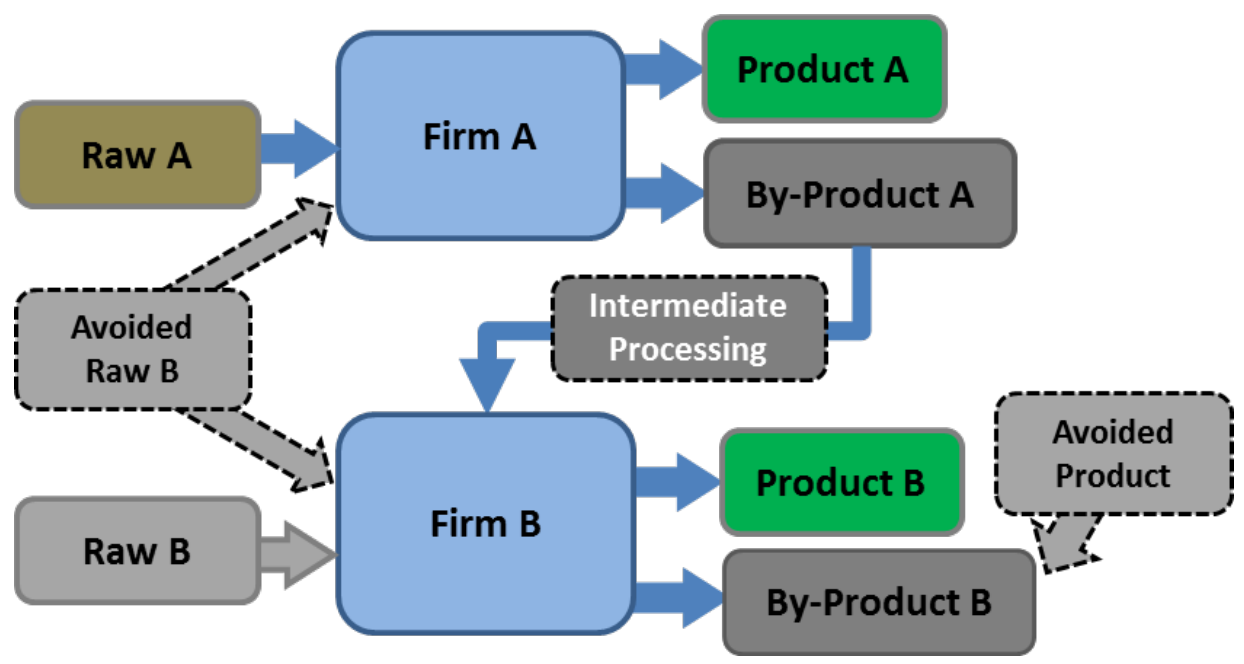

Figure 5: Illustration of the 50/50 method, including possible intermediate processing and avoided raw materials and products, for the exchange of By-Product A between Firm A and B.

Figure 5 offers an illustration of this approach for an IS network. In Figure 5 credits are provided to Firm A and B for the avoidance of Raw B from the use of By-Product A. In this approach, since By-Product A removes Raw B, 50\% of the impacts of Raw B are removed from Product $A$ and $50 \%$ from Product $B$. The impacts from the production of Raw B are still applied to Firm B in order to avoid double-counting of credits created by the avoidance and to model changes in the production of Raw B.

The credits from the avoidance of impacts to produce Raw B ( $\left.I_{\text {RawB }}\right)$ for the supply of ByProduct $A$ are therefore partitioned to reflect both the supply and demand for By-Product $A$. Impacts associated with Products A $\left(I_{E A}\right)$ and B $\left(I_{E A}\right)$ are given in Equations 1 and 2 for the method, which include the impacts from processing and other inputs in Firm A ( $\left.I_{\text {FirmA }}\right)$ and Firm B $\left(I_{\text {FirmB }}\right)$.

Eq. (1) $I_{\text {EA }}=I_{\text {FirmA }}-0.5\left(I_{\text {RawB }}\right)$

Eq. (2) $I_{E B}=I_{\text {FirmB }}+I_{\text {RawB }}-0.5\left(I_{\text {RawB }}\right)=I_{\text {FirmB }}+0.5\left(I_{\text {RawB }}\right)$

Furthermore, in order to enable an exchange, an intermediate process may be needed to upgrade or change the properties of a by-product. In this case the impacts from the intermediate process should be equally split between the Firm A and B and applied to the impacts for Product A and B; see Equations 3 and 4.

Eq. (3) $I_{E A}=I_{\text {FirmA }}-0.5\left(I_{\text {RawB }}\right)+0.5\left(I_{\text {Intermediate }}\right)$

$E q .(4) I_{E B}=I_{\text {FirmB }}+0.5\left(I_{\text {RawB }}\right)+0.5\left(I_{\text {Intermediate }}\right)$ 


\subsection{Reference Scenario Allocation}
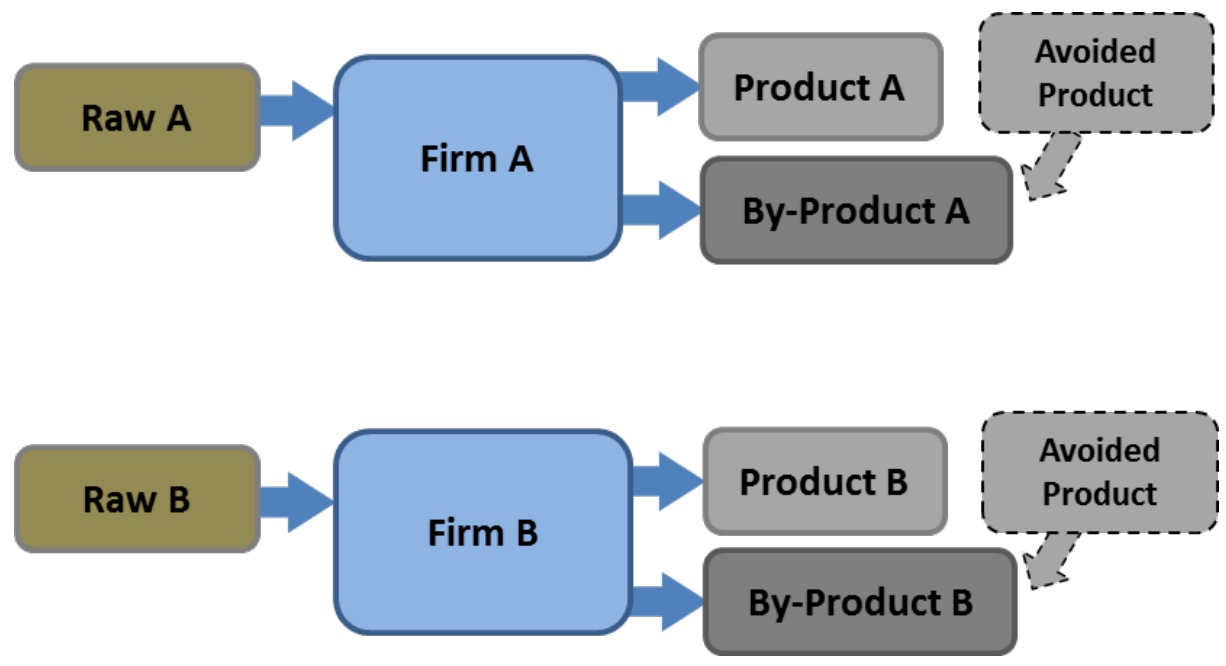

Figure 6: Reference system with no exchanges. If system expansion method is used, the avoided conventional products would be deducted from the impacts.

Figure 6 illustrates a reference or stand-alone scenario with no exchanges. In the reference scenario, Firm A produces Product A and By-Product A and Firm B produces Product B and By-Product B. For the allocation of impacts, physical allocation or system expansion may be applied.

Using physical allocation, impacts may be partitioned to both Product A and By-Product A based on their physical properties; similarly for Product B and By-Product B. If physical allocation is chosen, the physical parameter used to allocate impacts must be consistent for all firms and scenarios used in the quantification.

If system expansion is chosen, the production of By-Product A and By-Product B displace respective conventional products. The impacts of producing these conventional products are therefore removed from the impact of Product A and B respectively. 


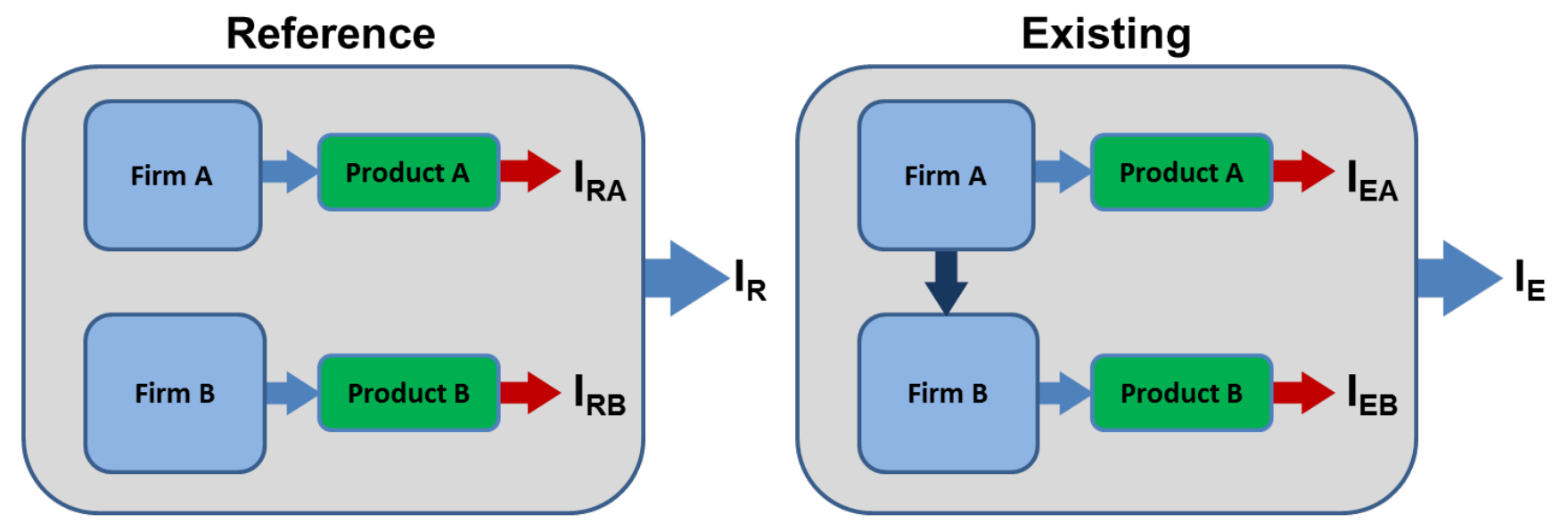

Figure 7: Illustration of the environmental Impacts from Products A and B for the Reference Scenario with no exchanges and the Existing Scenario for the IS network. Only the main products of each respective scenario are represented. $I_{R A}$-Impact Product A-Reference Scenario, $I_{R B}$-Impact Product B-Reference Scenario, $I_{R}$-Total Impact-Reference Scenario, $I_{E A}$-Impact Product A-Existing Scenario, $I_{E B}$-Impact Product B-Existing Scenario, $I_{E}$-Total Impact-Existing Scenario.

In order to find the share of the impact due to each main product (functional unit(s)) of the IS network, the quantifications are conducted separately using either physical allocation or the system expansion methods outlined previously. Figure 7 provides an illustration of the impacts from the reference and existing scenarios for the exchanges between Firm A and B, using the exchanges from previous figures for consistency. However, the IS network could include further exchanges which can be accounted for in the provided approach. Furthermore, scenarios could be built to test the existing scenario with improved scenarios.

The total impact of the reference scenarios $\left(I_{R}\right)$ is equal to the sum of the impacts from the different main products $\left(I_{R A}\right.$ and $\left.I_{R B}\right)$; see Equation 5. Similarly, the total impact of the existing scenario $\left(I_{E}\right)$ is equal to the sum of the impacts from the different main products $\left(I_{E A}\right.$ and $I_{E B}$ ); see Equation 6.

Eq. (5) $I_{R}=I_{R A}+I_{R B}$

Eq. (6) $I_{E}=I_{E A}+I_{E B}$

In order to find the net benefit or impacts provided to each product ( $I_{\text {Net-ProdA }}$ and $I_{\text {Net-ProdB }}$ for Products A and B respectively), the impacts from each product in the different scenarios are compared.

Eq. (7) $I_{\text {Net-ProdA }}=I_{R A}-I_{E A}$

Eq. (8) $I_{\text {Net-ProdB }}=I_{R B}-I_{E B}$ 
From Equations 7 and 8, the net benefits or impacts for each firm may be assessed. The net benefits or impacts of the industrial symbiosis network $\left(I_{\text {Net-IS }}\right)$ will equal the sum of the net benefits or impacts of the main products, shown in Equation 9; which is equivalent to Equation 10.

Eq. (9) $I_{\text {Net-IS }}=I_{\text {Net-ProdA }}+I_{\text {Net-ProdB }}$

\subsection{Total System Impacts}

The environmental performance benefits or impacts of each firm can be reviewed by analyzing the difference in scenarios, e.g. reference vs. existing scenario (or existing vs. a system with proposed improvements). The environmental performance can thereafter be measured based on the approach provided in this text for the industrial symbiosis network.

For the scenario comparison, the life cycle assessment is performed using the functional unit defined, i.e. main products of the system. The difference of scenarios will show whether a net benefit or impact is produced from the industrial symbiosis network compared to a reference scenario, see Equation 9 and Figure 7. This can be done to test the reference scenario(s) against the existing scenario.

Eq. (10) $I_{\text {Net-IS }}=I_{R}-I_{E}$ 


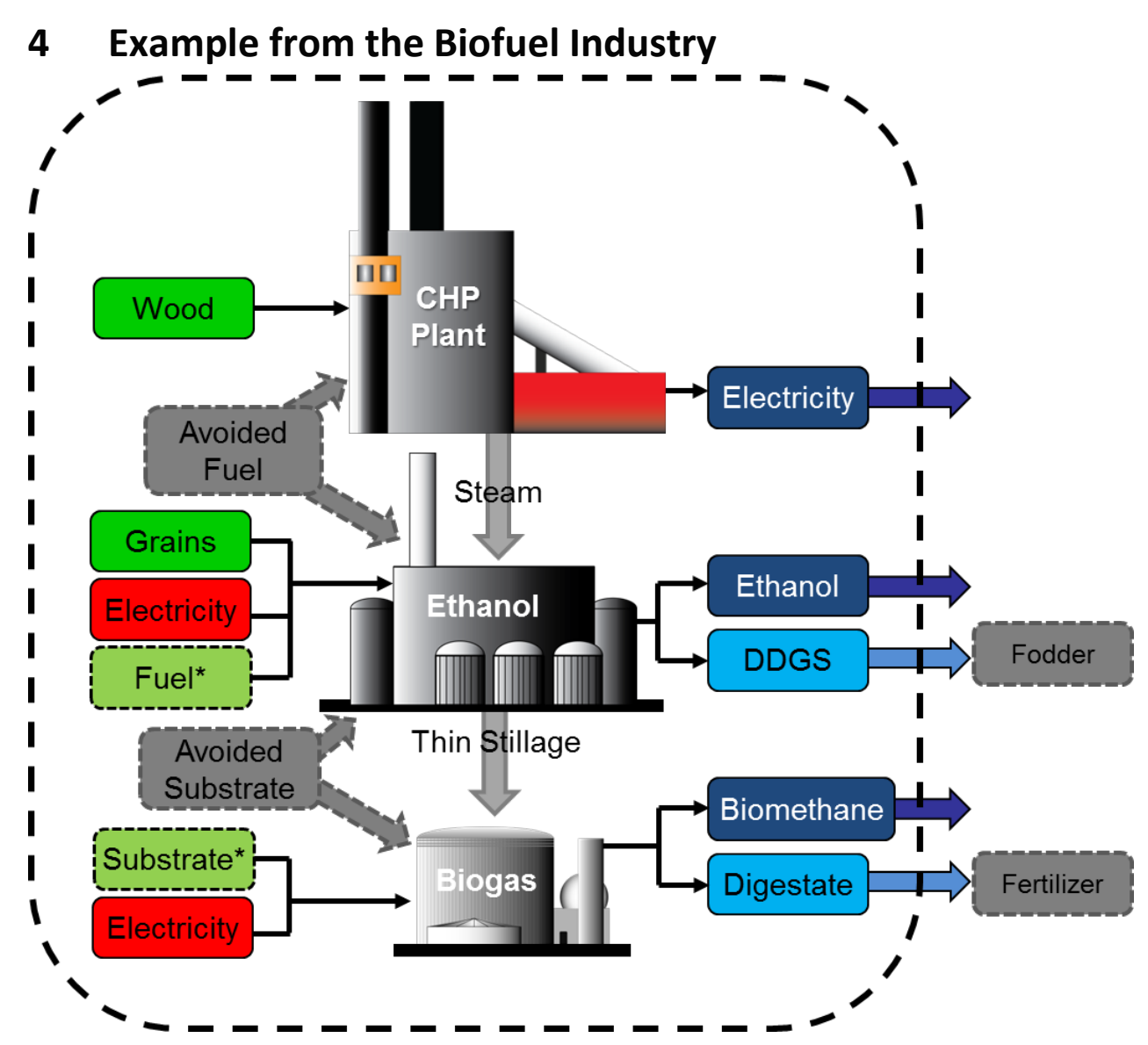

Figure 8: Illustration of a fictitious IS network. Dark arrows leaving the system boundary represent the functional units of the system. By-products of the system substitute the specified conventional products, i.e. fodder and fertilizer. Impacts from the avoided substrate and fuel, due to the exchange of thin stillage and steam respectively, are credited to the firms involved in the exchanges. Impacts are still applied to the ethanol and biogas plants for the use of steam and thin stillage, labeled Fuel* and Substrate* respectively.

Figure 8 provides an illustration of a fictional IS network including combined heat and power (CHP), biogas and ethanol plants, with some inputs excluded for simplicity. Stillage from the ethanol plant is used as the main substrate for biogas production, avoiding conventional substrate. Steam from the CHP plant is used for process energy in the ethanol plant, avoiding conventional fuel. The functional units of the IS network are set to the output of ethanol, biomethane and electricity produced by the CHP plant. The ethanol plant produces dried distillers grains with solubles (DDGS) as a by-product, used as fodder. The biogas plant produces digestate which is used as a fertilizer.

Using the 50/50 method as outlined in this paper would therefore allow for a credit for the impacts from the avoided substrate to be deducted from the impacts for the biogas and ethanol processes, however, the biogas plant would still receive an impact for the conventional substrate. Furthermore, a credit is also applied due to the use of steam from 
the CHP plant in the ethanol plant. The ethanol plant also receives an impact for the conventional fuel used in place of the steam.

Table 1: Notations for the impacts from processes and products of Figure 8.

\begin{tabular}{cc}
\hline Process/Product & Variable Notation \\
\hline Ethanol Plant Emissions & $I_{\text {EthanolProcess }}$ \\
\hline Biogas Plant Emissions & $I_{\text {BiogasProcess }}$ \\
\hline CHP Plant Emissions & $I_{\text {CHP }}$ \\
\hline Wood for CHP Plant & $I_{\text {Wood }}$ \\
\hline Grains & $I_{\text {Grains }}$ \\
\hline Substrate & $I_{\text {Substrate }}$ \\
\hline Electricity Use (Swedish- & $I_{\text {El_SWE }}$ \\
\hline El. Grid) & $I_{\text {Fuel }}$ \\
\hline Fuel & $I_{\text {Substrate }}$ \\
\hline Substrate & $I_{\text {Fertilizer }}$ \\
\hline Conventional Fertilizer & $I_{\text {Fodder }}$ \\
\hline Conventional Fodder & $I_{\text {Ethanol }}$ \\
\hline Ethanol & $I_{\text {Biomethane }}$ \\
\hline Biomethane & $I_{\text {Electricity }}$ \\
\hline Electricity Produced & $I_{\text {IS-Net }}$ \\
\hline IS Network &
\end{tabular}

Equations 11-14 will provide examples for the quantifications of impacts for the IS network using the 50/50 method as illustrated in Figure 8 to provide the impacts for the individual firms of the IS networks. Variable notations for the impacts from the processes and products are provided in Table 1.

Eq. (11) $I_{\text {Electricity }}=I_{\text {Wood }}+I_{C H P}-0.5\left(I_{\text {Fuel }}\right)$

Eq. (12) $I_{\text {Ethanol }}=I_{\text {EthanolProcess }}+I_{\text {Grains }}+I_{\text {El_SWE }}+0.5\left(I_{\text {Fuel }}\right)-0.5\left(I_{\text {Substrate }}\right)-I_{\text {Fodder }}$

Eq. (13) $I_{\text {Biomethane }}=I_{\text {BiogasProcess }}+I_{\text {El_SWE }}+0.5\left(I_{\text {Substrate }}\right)-I_{\text {Fertilizer }}$

Eq. (14) $I_{\text {IS-Net }}=I_{\text {Biogas }}+I_{\text {Ethanol }}+I_{\text {Electricity }}$ 


\section{Discussion}

Previous attempts to quantify industrial symbiosis networks have lacked structured methods for the quantifications. The approach provided in this paper has therefore addressed many of the previous methodological concerns using life cycle assessment as a background. Nonetheless, the approach also has its limits and can again be influenced by the choices made, similar to LCA studies. The following sections provide a discussion on the strengths and weaknesses of the approach including the methodological choices made, their influence and the implications of the method for the IS research community and firms of an IS network.

\subsection{System Boundaries and Functional Unit}

Many of the previous environmental performance quantifications of IS networks have focused on providing the reduction in energy and material consumption. Van Berkel et al. (2009) argue that modeling only the reduction in material consumption and energy use may underestimate the environmental impacts associated with the sharing of resources. In order to show the impacts from the IS network for both upstream and downstream processes, Sokka (2011), in addition to other authors e.g. (Mattila et al., 2012; Singh et al., 2007), argue that quantitative life cycle based methods are needed.

In the approach outlined in this paper, the downstream processes have been "cut-off" from the processes as the aims of the approach are to provide the total impacts of the IS network and the possible impacts and benefits for firms involved in the IS network due to the exchanges of material and energy. Ekvall et al. (Ekvall et al., 2007) claim that LCAs greatly simplify complex realities and should focus on the parts of the system expected to be affected by changes. The cutoff is done in order to maintain the confined constraints of the project. As industrial symbiosis networks may contain a number of exchanges and products, the systems can become very complex and would produce results that may not be usable for the firms of the IS network according to the goal and scope outlined. Therefore, including downstream processes is beyond the scope of the presented approach, and if the downstream impacts are to be portrayed, the goal and scope of the assessments must warrant this.

Furthermore, it is argued in this paper that by only showing the total impacts of the IS network, studies may fail to present employable data for firms in the industrial symbiosis network. The approach outlined in this paper can provide data to be used for the firms of the industrial symbiosis network to identify impacts and benefits from the exchanges and possibly identify processes which could be improved. From this information further exchanges may be implemented to ultimately improve the environmental performance and have further implications, described subsequently. 


\subsection{Allocation of Impacts}

The approach provided in this paper outlines and describes using different allocation methods. Again, it is also recommended that both physical allocation and system expansion for the quantifications are used in order to show the influence they may have on the results. This is done in order to highlight the importance of the choice of allocation method, as the choice is considered controversial in the LCA literature and there is no correct way or consensus on how to solve the problem (Ekvall and Finnveden, 2001; Guinée et al., 2004; Wardenaar et al., 2012). Nonetheless, many studies, e.g. in the biofuel industry, provide quantifications using both methods (van der Voet et al., 2010) in order to show the influence on the results.

Industrial symbiosis networks are modeled with a limited number of exchanges in the approach of this paper to simplify the examples. This does not limit the possibilities for multiple exchanges, as the actual number of exchanges and quantity of raw materials may be more complex than the simple examples provided. However, further exchanges may make the allocation of impacts more complex; though once again they are not limited by the method.

Determination of the details associated with the allocation methods may also present difficulties. The choice of physical parameter for the physical allocation method has been outlined as an influential choice for the results; see e.g. (Ayer et al., 2007; Cherubini, 2010; van der Voet et al., 2010). Energy allocation is considered advantageous due to the fact that relationships between the by-products are constant, while economic allocation may fluctuate (Börjesson, 2009). Nonetheless, the choice depends upon the goal and scope of the study and the characteristics of the products and by-products of the study must therefore be considered when choosing the allocation method. It is recommended that several parameters are also tested, within the constraints of the assessments being produced, to show the influence this may have on the results.

The applicability of the 50/50 method outlined may also be questioned outside of the simple exchanges provided in this paper. The method outlined can include intermediate processing before a by-product is used as a raw material in another industry. However, this is a situation that the open-loop recycling literature avoids by applying impacts to the first producer and final user of a material (Ekvall and Tillman, 1997; Ekvall, 2000). In the approach outlined, the impacts from intermediate processing are to be distributed between the firms involved in the exchange. However, in the approach of Weidema (2001) the impacts are applied to the firm which the by-product originates from, assuming the byproduct is fully utilized. Once again however, the equal distribution outlined in this paper for an intermediate process attempts to distribute the impacts to promote the exchanges. This fair distribution among firms may be questioned. If the material used in the exchange is classified as a waste, the use of this equal distribution may not be justified and is 
therefore applicable only to by-products which are not considered wastes. Additionally, as identified in the results, some firms may not benefit from the exchanges and therefore delivering further impacts may not be appropriate. The equal distribution also assumes that both firms may benefit from the exchange by reducing raw material consumption which, in a systems perspective, may not be the case. Nonetheless, the 50/50 method should be seen as an example of an approach to partition the impacts between firms of the IS network.

Other choices in the 50/50 method may also present difficulties. An example is the choice of avoided conventional raw material. Rarely products are mono-functional, and are usually products of other processes which must be taken into account (Heijungs and Guinée, 2007). Therefore, the data used for the avoided conventional raw material must be made transparent and also contain some cut-off criteria.

The choice of conventional raw materials and products replaced by by-products of the system in the 50/50 method and system expansion methods are of importance to the assessment. Their choice may lead to differing results, and once again motivation for these choices is required (Ekvall and Weidema, 2004; Weidema, 2001; Weidema et al., 1999). When by-products are used in a subsequent firm, their quality may not be the same as the replaced conventional product. Quality must therefore be taken into account, as e.g. $1 \mathrm{~kg}$ of a by-product may not be equivalent to $1 \mathrm{~kg}$ of the conventional product, therefore an analysis of the properties of the material are important (Ekvall and Weidema, 2004).

\subsubsection{Reference System}

Choosing to compare the existing scenario with several reference scenarios will provide a sensitivity analysis to deal with some of the uncertainties for the choices made in the reference case. A similar approach has been used by Sokka (2011) to show how different energy system choices may influence the results. However, when several firms are involved in the industrial symbiosis network, testing changes for different by-product streams for each firm may lead to a large number of reference scenarios to test each change. This can also be overcome by reviewing "hot spots" in the in the LCA of the reference scenario and changing the parameters which impact the system to the largest extent in order to construct new reference scenarios (Guinée, 2002).

Furthermore, the choice of by-product streams in the reference scenario is also important. As van Berkel (2010) discusses, whether a by-product can be avoided by conventional products is uncertain. If no symbiotic activity was present, it is possible that the by-product may not be produced at all, due to optimization of the by-product stream. For example, if improvements to the by-product streams would have occurred, the value and quality of these and replaced conventional products may change, potentially reducing the impact of the reference scenarios. 
In the reference scenario analysis, it was recommended that a marginal energy system be chosen in one of the scenarios. This choice may have large impacts on the environmental performance of industrial the symbiosis network of study if current energy supply is from renewable sources (Börjesson, 2009; Sokka, 2011; Wolf and Karlsson, 2008).

\subsubsection{Conducting Several Separate Quantifications}

Using the current approach calls for the production of a life cycle assessment for all main products of the system, for which quantifications are conducted separately in order to achieve the benefits and impacts of symbiotic activities. Only by producing separate LCAs with knowledge of the other processes can the benefits and impacts of the symbiotic activity be assessed. Although this may require a larger workload for the practitioner of the IS network quantification, conducting a separate quantification for each main product will allow for the net impacts and benefits for the firms to become transparent. Furthermore, conducting each separately with no regard to the others will possibly lead to doublecounting of benefits and impacts of the exchanges.

\subsection{Use of the approach for quantifying other IS Networks}

The approach outlined in this paper was designed to provide guidance to quantify the environmental performance of IS networks and provide the total impacts of an industrial symbiosis network in addition to the impacts for individual firms. However, it may not be applicable to answer all research questions in other IS networks. The approach is best suited for quantifications of current IS networks versus reference scenarios, though future scenarios based on the current IS network may be modeled. The approach is less well suited for reviewing extensive changes, e.g. the design of eco-industrial parks, reviewing the use of IS versus other options and assessment of circular economies, and is thus limited by the system boundaries chosen; see e.g. Mattila et al. (2012). However, the methodological considerations may be used in other studies for quantifying IS networks. Although not addressed earlier, the method does not avoid the possibility to use hybrid-methods to take into account more upstream impacts, as outlined by e.g. (Mattila et al., 2010). This can be done by changing any of the methodological choices used in the approach provided.

The approach provided in this paper has been applied to an IS network in the biofuel industry in a PhD thesis; see (Martin, 2013). The IS network quantified is similar to the IS network provided in Figure 8. However, in order to give credibility to the approach and identify further developments, it is recommended to be applied in other cases using the generic approach provided. 


\subsection{Implications for firms involved in an industrial symbiosis network}

The implications of analyzing the environmental performance extend beyond quantifying the total impacts and net benefits of IS networks. Therefore, a focus on the firms and products of the symbiosis has been used in this paper. The benefits or impacts present for individual firms involved in the IS network may influence taxes, subsidies, environmental consent, etc. (Wolf and Karlsson, 2008). This is especially true when firms must meet environmental regulations and report their environmental performance. Providing a partitioning of credits to firms in the industrial symbiosis network due to exchanges may also be used in facilitating industrial symbiosis for business relations, optimization of processes and communication of environmental performance (Wolf and Petersson, 2007). For example, in the biofuel industry such crediting from symbiotic activities may have implications for the sustainability guidelines for biofuels set forth by the Renewable Energy Directive (European Union, 2009). Currently in the directive, assessments must be conducted separately. Credits from material and energy exchanges may not be allowed for in the environmental performance standards, though use of by-products and wastes is promoted for biofuel production (Rangaraju, 2011).

From the approach, the identification of those firms benefiting or being impacted from the symbiotic activity may help to identify key actors in the industrial symbiosis network, e.g. the anchor tenant and those firms benefiting most from the symbiosis network (Wolf and Karlsson, 2008). Information as such may lead to data for the motivation of new exchanges, particularly when more than economic benefits can be reviewed. However, the contrary is also true, and if the quantifications provide little benefits for some firms, they may pull out of the symbiotic activity and use conventional raw materials as an alternative. In some cases firms may benefit more by not exchanging materials and energy, as the benefits from avoided conventional products outweigh those produced through the exchange and subsequent avoided conventional raw material. This has been observed in the biofuel industry where ethanol producers produce a fodder. The credits for the avoidance of conventional fodder outweigh those of using the fodder for biogas and subsequent biofertilizer production (Martin et al., In Press). This may therefore provide motivation for negotiations for pricing of the by-products. 


\section{Conclusions}

From a review of previous quantifications of IS networks, it was concluded that guidelines and criteria for conducting environmental performance quantifications of IS networks are lacking in the literature. This paper has provided an approach for quantifying the environmental performance of industrial symbiosis networks using guidance from the literature of life cycle assessment. Important factors for quantifying the environmental performance of IS networks have been identified, including the functional unit, reference scenario selection, use of system expansion method versus physical allocation and choice of avoided conventional products and raw materials. An approach for crediting firms for exchanged material and energy has also been examined. The net benefits and impacts produced for each firm of the IS network have been identified to have implications for taxes and subsidies, business relations and the communication of the environmental performance for firms in the IS network. However, similar to life cycle assessments, the methodological choices for the quantifications of the environmental performance of IS networks may influence the results. As the approach has been designed to address the comparison of an IS network to a reference scenario, it may not be applicable to answer the aims of all quantifications of IS networks, though it can provide guidance and recommendations for methodological considerations. Finally, the identification of who "benefits" from the IS network is not easy to define, though in this paper the benefits from being in the IS network are recommended to be shared among the firms involved in exchanges equally to promote the exchanges.

\section{References}

Ayer, N.W., Tyedmers, P.H., Pelletier, N.L., Sonesson, U., Scholz, A., 2007. Co-product allocation in life cycle assessments of seafood production system: Review of problems and strategies. Int. J. Life Cycle Ass. 6, 357-369.

Börjesson, P., 2009. Good or bad bioethanol from a greenhouse gas perspective - What determines this? Appl. Energ. 5, 589-594.

Chertow, M.R., 2000. Industrial symbiosis: Literature and taxonomy. Annu. Rev. Energy Environ. 25, 313-337.

Chertow, M.R., Lombardi, D.R., 2005. Quantifying economic and environmental benefits of co-located firms. Environ. Sci. Technol. 17, 6535-6541.

Cherubini, F., 2010. GHG balances of bioenergy systems - Overview of key steps in the production chain and methodological concerns. Renew. Energ. 7, 1565-1573. 
Ekvall, T., Tillman, A.-., 1997. Open-loop recycling: Criteria for allocation procedures. Int. J. Life Cycle Ass. 3, 155-162.

Ekvall, T., Weidema, B.P., 2004. System boundaries and input data in consequential life cycle inventory analysis. Int. J. Life Cycle Ass. 3, 161-171.

Ekvall, T., 2000. A market-based approach to allocation at open-loop recycling. Resour. Conserv. Recycling. 1-2, 91-109.

Ekvall, T., Assefa, G., Björklund, A., Eriksson, O., Finnveden, G., 2007. What life-cycle assessment does and does not do in assessments of waste management. Waste Manage. 8, 989-996.

Ekvall, T., Finnveden, G., 2001. Allocation in ISO 14041-a critical review. J. Clean. Prod. 3, 197-208.

European Commission, 2010. General guide for Life Cycle Assessment - Detailed guidance. International Reference Life Cycle Data System.

European Union, 2009. Directive 2009/28/EC of the European Parliament and of the Council of 23 April 2009 on the promotion of the use of energy from renewable sources and amending and subsequently repealing Directives 2001/77/EC and 2003/30/EC. L140/1662: Official Journal of the European Union

Finnveden, G., Hauschild, M.Z., Ekvall, T., Guinée, J., Heijungs, R., Hellweg, S., Koehler, A., Pennington, D., Suh, S., 2009. Recent developments in Life Cycle Assessment. J. Environ. Manage. 1, 1-21.

Guinée, J.B., 2002. Handbook on Life Cycle Assessment: Operational guide to the ISO standards. Kluwer Academic Publishers, Dordrecht, The Netherlands.

Guinée, J.B., Heijungs, R., Huppes, G., 2004. Economic Allocation: Examples and Derived Decision Tree. Int. J. Life Cycle Ass. 1, 23-33.

Heijungs, R., Guinée, J.B., 2007. Allocation and 'what-if' scenarios in life cycle assessment of waste management systems. Waste Manage. 8, 997-1005.

ISO, 2006a. ISO 14040:2006 Environmental management-life cycle assessment-principles and framework.International Organization for Standardization.

ISO, 2006b. ISO 14044:2006 Environmental management -Life cycle assessment Requirements and guidelines. International Organization for Standardization.

Jacobsen, N.B., 2006. Industrial symbiosis in Kalundborg, Denmark: A quantitative assessment of economic and environmental aspects. J. Ind. Ecol. 1-2, 239-255. 
Martin, M., Svensson, N., Eklund, M., 2012. Who gets the benefits? An approach for assessing the environmental performance of industrial symbiosis. Greening of Industry 2012 Conference Proceedings.

Martin, M., 2013. Industrial Symbiosis in the Biofuel Industry: Quantification of the Environmental Performance and Identification of Synergies. PhD Dissertation, Linköping University, Environmental Technology and Management. ISBN: 978-91-7519-658-9.

Martin, M., Svensson, N., Eklund, M., Fonseca, J., In Press. Quantifying the Environmental Performance of Integrated Bioethanol and Biogas Production. Renew. Energ. DOI: http://dx.doi.org/10.1016/j.renene.2012.09.058.

Martin, M., Eklund, M., 2011. Improving the environmental performance of biofuels with industrial symbiosis. Biomass Bioenerg. 5, 1747-1755.

Mattila, T., Lehtoranta, S., Sokka, L., Melanen, M., Nissinen, A., 2012. Methodological Aspects of Applying Life Cycle Assessment to Industrial Symbioses. J. Ind. Ecol. 1, 51-60.

Mattila, T.J., Pakarinen, S., Sokka, L., 2010. Quantifying the total environmental impacts of an industrial symbiosis-a comparison of process-, hybrid and input-output life cycle assessment. Environ. Sci. Technol. 11, 4309-4314.

Rangaraju, S., 2011. Comparison of the LCA Methodologies of the ISO and Renewable Energy Directive: Implications for Industrial Symbiosis in the Biofuel Industry. Master of Science Thesis, , Linköping University. LIU-IEI-TEK-A--11/01249--SE.

Singh, A., Lou, H.H., Yaws, C.L., Hopper, J.R., Pike, R.W., 2007. Environmental impact assessment of different design schemes of an industrial ecosystem. Resour. Conserv. Recycling. 2, 294-313.

Sokka, L., 2011. Local systems, global impacts: Using life cycle assessment to analyse the potential and constraints of industrial symbioses. PhD Dissertation, VTT Technical Research Centre of Finland. VTT Publication 768.

Sokka, L., Lehtoranta, S., Nissinen, A., Melanen, M., 2011. Analyzing the Environmental Benefits of Industrial Symbiosis: Life Cycle Assessment Applied to a Finnish Forest Industry Complex. J. Ind. Ecol. 1, 137-155.

van Berkel, R., 2010. Quantifying Sustainability Benefits of Industrial Symbioses. J. Ind. Ecol. 3, 371-373.

van der Voet, E., Lifset, R.J., Luo, L., 2010. Life-cycle assessment of biofuels, convergence and divergence. Biofuels. 3, 435-449. 
Wardenaar, T., Van Ruijven, T., Beltran, A.M., Vad, K., Guinée, J., Heijungs, R., 2012. Differences between LCA for analysis and LCA for policy: A case study on the consequences of allocation choices in bio-energy policies. Int. J. Life Cycle Ass. 8, 1059-1067.

Weidema, B., 2001. Avoiding co-product allocation in life-cycle assessment. J. Ind. Ecol. 3, 11-33.

Weidema, B.P., Frees, N., Nielsen, A.-., 1999. Marginal production technologies for life cycle inventories. Int. J. Life Cycle Ass. 1, 48-56.

Wolf, A., Karlsson, M., 2008. Evaluating the environmental benefits of industrial symbiosis: Discussion and demonstration of a new approach. Prog. Ind. Ecol. 5-6, 502-517.

Wolf, A., Petersson, K., 2007. Industrial symbiosis in the Swedish forest industry. Prog. Ind. Ecol. 5, 348-362.

Zamagni, A., Guinée, J., Heijungs, R., Masoni, P., Raggi, A., 2012. Lights and shadows in consequential LCA. Int. J. Life Cycle Ass. 7, 904-918. 